\title{
Anticorpo monoclonal antiAFB : produção in vitro visando desenvolvimento de bioferramentas
}

\author{
Monoclonal antibody anti-AFB : $_{1}$ \\ scale-up in vitro for biotools development
}

\author{
Cássia Reika Takabayashi ${ }^{1}$; Luciana Hayashi ${ }^{1}$; Tatiane Martins de Oliveira ${ }^{2}$; \\ Simone Fujii ${ }^{3}$; Carlos Kemmelmeier ${ }^{4}$; Elisabete Yurie Sataque Ono \\ Eiko Nakagawa Itano ${ }^{6}$; Osamu Kawamura ${ }^{7}$; Elisa Yoko Hirooka ${ }^{8^{*}}$
}

\section{Resumo}

\begin{abstract}
Aflatoxina $\mathrm{B}_{1}\left(\mathrm{AFB}_{1}\right)$ é uma micotoxina classificada pela International Agency for Research on Cancer - IARC no Grupo 1 (carcinógeno ao humano), responsável pelo perigo de contaminação em ampla variedade de alimento e ração, cujo monitoramento depende de metodologia analítica precisa e exata. O trabalho objetivou no cultivo do hibridoma secretor de anticorpo monoclonal (AcM) específico para $\mathrm{AFB}_{1}$ visando desenvolvimento de métodos imunoquímicos. Hibridoma AF2 foi cultivado em meio RPMI $+15 \%$ de soro fetal bovino (SFB), assim como o mesmo meio com adição gradual de meio H-SFM $(25,50,75$ e $100 \%$ H-SFM). A concentração proteica obtida no sobrenadante de cultura variou de 1,80 a $10,88 \mathrm{mg} / \mathrm{mL}$. A introdução de meio sintético H-SFM isento de SFB permitiu obtenção de reagente com maior pureza e menor perigo, já que cultivos com maior proporção de H-SFM apresentou menor teor proteico $(2,29 \mathrm{mg} / \mathrm{mL}$ em $100 \%$ de H-SFM), sendo este provavelmente próximo ao teor real de AcM puro. O ensaio imunoenzimático competitivo indireto (ic-ELISA) e eletroforese em gel

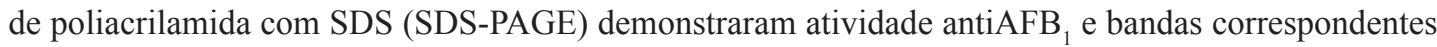
ao IgG, respectivamente, indicando viabilidade da aplicação de AcM produzido em 100, 75 e $50 \%$ H-SFM para o desenvolvimento de bioferramentas para detecção de $\mathrm{AFB}_{1}$. Esta produção de AcM abre perspectiva perante autossuficiência de reagentes essenciais no diagnóstico rápido em condição nacional, contribuindo na qualidade e segurança de alimentos.
\end{abstract}

Palavras-chave: Anticorpo monclonal, hibridoma, bioferramenta, $\mathrm{AFB}_{1}$

\footnotetext{
${ }^{1}$ Mestre em Ciência de Alimentos, Depto de Ciência e Tecnologia de Alimentos, Universidade Estadual de Londrina, UEL, Londrina, PR. Endereço: Rod. Celso Garcia Cid, PR 445 Km 380- CCA/DCTA. CEP 86055-900.Telefone: 3371-5963. E-mail: kcia_rt@yahoo.com.br; lucianahayashi@gmail.com

${ }^{2}$ Mestranda em Ciência de Alimentos, Depto de Ciência e Tecnologia de Alimentos, UEL, PR. E-mail: tatianeoliveira_z@hotmail. com

${ }^{3}$ Doutora em Ciência de Alimentos, Depto de Ciência e Tecnologia de Alimentos, UEL, Londrina, PR. E-mail: simone_fujii@, yahoo.com.br

${ }^{4}$ Professor Titular, Depto. Bioquímica, Universidade Estadual de Maringá, UEM, Maringá, PR. E-mail: ckemmelmeier@uem.br

${ }^{5}$ Professora Associada, Depto. Bioquímica e Biotecnologia, UEL, Londrina, PR. E-mail: eysono@hotmail.com

${ }^{6}$ Professora Associada, Depto de Ciências Patológicas, UEL, Londrina, PR. E-mail: itanoeiko@hotmail.com

${ }^{7}$ Professor Titular, Department of Biochemistry and Food Science, Faculty of Agriculture, Kagawa University, Kagawa, Japan. E-mail: kawamura@ag.kagawa-u.ac.jp

${ }^{8}$ Professora Associada, Depto de Ciência e Tecnologia de Alimentos, UEL, Londrina, PR. E-mail: hirooka@uel.br

* Autor para correspondência
} 


\begin{abstract}
Aflatoxin $\mathrm{B}_{1}\left(\mathrm{AFB}_{1}\right)$ is a mycotoxin classified as group 1 (human carcinogen) by International Agency for Research on Cancer - IARC, causing hazardous contamination in a wide variety of food and feed, where the monitoring depends on precision and accuracy of analytical method. The culture of $\mathrm{AFB}_{1}$ specific monoclonal antibody $(\mathrm{mAb})$ secreting hybridoma was performed for further development of immunochemical methods. The growth of hybridoma AF2 was carried out in RPMI medium $+15 \%$ fetal bovine serum (FBS), as well as the same medium gradually amended with H-SFM medium $(25,50$, 75 and $100 \% \mathrm{H}-\mathrm{SFM}$ ). The protein concentration in the culture supernatant ranged from 1.80 to 10.88 $\mathrm{mg} / \mathrm{mL}$. The culture amended with FBS-free synthetic H-SFM medium reached production of reagent with higher degree of purity and lower risk, in addition to lower protein content $(2.29 \mathrm{mg} / \mathrm{mL}$ reached with $100 \% \mathrm{H}-\mathrm{SFM}$ ), which approaches the real content of pure $\mathrm{mAb}$. The indirect competitive enzymelinked immunosorbent assay (ic-ELISA) and SDS-polyacrylamide gel electrophoresis (SDS-PAGE) showed anti-AFB $\mathrm{B}_{1}$ activity and $\mathrm{IgG}$ corresponding bands, respectively, indicating feasible application of $\mathrm{mAb}$ produced in 100, 75 and $50 \% \mathrm{H}$-SFM for further use in the development of AFB detecting biotools. This $\mathrm{mAb}$ production can be an initial step that can supply the self-sufficient immune-reagent in the rapid diagnosis at national condition, which is essential in the food quality and safety.
\end{abstract}

Key words: Monoclonal antibody, hybridoma, biotool, $\mathrm{AFB}_{1}$

\section{Introdução}

Aflatoxinas (AFs) são bisfurano-cumarinas pertencentes ao metabolismo secundário da via de policetídeo, produzidas principalmente por Aspergillus flavus, A. parasiticus e A. nomius (JAIMEZ et al., 2000; CHIAVARO et al., 2001; $\mathrm{CHO}$ et al., 2008). AFs ocorrem em ampla variedade de alimento, a exemplo de cevada, milho, arroz, nozes, pistache, pimenta, amendoim, carne, leite, ovo e respectivos produtos derivados (JAIMEZ et al., 2000; IP; CHE, 2006; CALLERI et al., 2007; ARDIC et al., 2008).

Aflatoxina $\mathrm{B}_{1}\left(\mathrm{AFB}_{1}\right)$ é a micotoxina mais tóxica, classificado pela International Agency for Research on Cancer (IARC, 2002) no Grupo 1, i.e. carcinógeno ao humano. O Brasil estabeleceu limite máximo tolerável de $\mathrm{AF}$ total $\left(\mathrm{B}_{1}+\mathrm{B}_{2}+\mathrm{G}_{1}+\mathrm{G}_{2}\right)$ para milho, amendoim e produtos derivados em $20 \mu \mathrm{g} /$ $\mathrm{Kg} ; \mathrm{AFM}_{1}$ para leite fluído em $0,5 \mu \mathrm{g} / \mathrm{L}$ e leite em pó em 5,0 $\mu \mathrm{g} / \mathrm{L}$ (ANVISA, 2002).

$\mathrm{O}$ monitoramento contínuo de $\mathrm{AFB}_{1}$ em alimento e ração é fundamental para diminuir o perigo à saúde humana e animal, fato este dependente de metodologia analítica precisa e exata (XIULAN et al., 2006; VAN EGMOND; NOGUER; CAMPÀS, 2007). Métodos tradicionais para determinação de AFs empregam cromatografia de camada delgada
(CCD), ou cromatografia líquida de alta eficiência (CLAE) acoplada a quantificação fluorimétrica (BRADBURN; COKER; BLUNDEN, 1995; XIULAN et al., 2006). O avanço introduziu espectrometria de massas (LC/MC ou LC-MS/ MS), cuja sofisticação permite confirmação do analito sem necessidade de manipulação pós-coluna (EDINBORO; KARNES, 2005; KRSKA et al., 2008).

Em contraste, tecnologias capazes de integrar controle de qualidade in-loco na cadeia produtiva exigem detecção rápida e simples, compactada em kits. A tecnologia inovadora baseada em anticorpo (Ac) surgiu como principal sistema alternativo biotecnológico isento de solventes orgânicos, evitando contaminação dos analistas e ambiente. Esta bioferramenta depende da produção irrestrita de Acs extremamente selecionados, com ênfase ao uso de hibridomas secretores de anticorpo monoclonal (mAb) em larga escala para implementar o sistema, a exemplo da coluna de imunoafinidade (CIA) para a limpeza e pré-concentração de extrato destinado à CLAE (SANCHEZ et al., 2007; CHO et al., 2008; KRSKA et al., 2008) e, imunoensaio (Enzyme-Linked Immunosorbent Assay - ELISA) para diagnóstico rápido na rotina (ANKLAM; STROKA; BOENKE, 2002; XIULAN et al., 2006; CALLERI et al., 2007). O enfoque atual em biosensores destaca o 
Ac entre sensores, capaz de combinar a atividade seletiva do elemento biológico ao sistema analítico, no contexto de nanobiotecnologia (KRSKA et al., 2008; PRIETO-SIMON; NOGUER; CAMPÀS, 2007; LUPPA; SOKOLL; CHAN, 2001).

O trabalho visou cultivo, manutenção e produção deAcM específico para $\mathrm{AFB}_{1}$ empregando hibridoma secretor AF2; cultivo em meio sintético isento de soro fetal bovino (SFB), seguido de concentração e purificação visando desenvolvimento de técnicas imunoquímicas para detecção de $\mathrm{AFB}_{1}$ em matrizes alimentares.

\section{Material e Métodos}

\section{Linhagem de hibridoma}

Para experimento foi utilizado hibridoma linhagem AF2 secretor de AcM específico para $\mathrm{AFB}_{1}$ (isotipo $\operatorname{IgG}_{1}$ lambda), derivada de mieloma linhagem SP2/0-AG14 e célula esplênica de camundongo BALB/c. Este hibridoma apresenta $133 ; 13,4$ e $14,7 \%$ de reatividade cruzada com $\mathrm{AFB}_{2}, \mathrm{AFG}_{1}$ e $\mathrm{AFG}_{2}$, respectivamente, conforme descrito na Tabela 1 (KAWAMURA et al., 1988).

Tabela 1. Reatividade cruzada de anticorpo monoclonal produzido por hibridoma linhagem AF2 com análogos de $\mathrm{AFB}_{1}$, analisadas por ic-ELISA.

\begin{tabular}{cc}
\hline Aflatoxina & \% reatividade cruzada \\
\cline { 2 - 2 } & AF2 \\
\hline $\mathrm{B}_{1}$ & 100 \\
$\mathrm{~B}_{2}$ & 133 \\
$\mathrm{G}_{1}$ & 13,4 \\
$\mathrm{G}_{2}$ & 14,7 \\
$\mathrm{AFL} \mathrm{I}^{\mathrm{a}}$ & 2 \\
$\mathrm{AFL} \mathrm{II}^{\mathrm{b}}$ & 5,5 \\
$\mathrm{M}_{1}$ & 0,9 \\
$\mathrm{Q}_{1}$ & $>0,5$ \\
$\mathrm{P}_{1}$ & 0,9 \\
$\mathrm{~B}_{2 \mathrm{a}}$ & $>0,5$ \\
\hline
\end{tabular}

a AFL I, isômero natural de [1S]-aflatoxicol

${ }^{\mathrm{b}}$ AFL II, isômero natural de [1R]-aflatoxicol ic-ELISA: Ensaio imunoenzimático indireto competitivo Fonte: KAWAMURA et al., 1988.
Cutivo de hibridoma e produção de AcM especifico para aflatoxina

\section{Manutenção e recuperação de hibridoma}

Os hibridomas estocados a $-185^{\circ} \mathrm{C}$ em nitrogênio líquido foram recuperados por descongelamento rápido de criotubo em banho a $37^{\circ} \mathrm{C}$, lavados com $15 \mathrm{~mL}$ de meio RPMI a $37^{\circ} \mathrm{C}$ e centrifugados (200x g, $5 \mathrm{~min}$ ). Descartado o sobrenadante, as células foram avaliadas microscopicamente (aumento de 100x, microscópio de fase invertida, Lamba LGD2, ATTO Instruments Co., China) com corante vital Azul de Trypan $(0,25 \%$ em meio RPMI, p/v) (Sigma Chemical Co., USA) e a viabilidade celular pós-congelamento foi calculada e expressa em porcentagem.

Para estimular a recuperação do hibridoma, as células foram ressuspendidas em meio RPMI 1640 (RPMI) com $30 \%$ soro fetal bovina (SFB) (Gibco Co., USA), 2 mM de glutamina (Gibco Co., USA), $23 \mathrm{mM}$ de bicarbonato de sódio (Synth, Brasil), 10 $\mathrm{mM}$ de HEPES (ácido N-(2-hidroxietil) piperazinaN'-2-etanossulfônico) (Acros Organics, USA) e $40 \mu \mathrm{g} / \mathrm{mL}$ de gentamicina (Schering Corporation, USA). O cultivo procedeu-se em microplaca de 24 orifícios (Corning, USA) e frasco de $25 \mathrm{~cm}^{2}$ (TPP, Suiça) a $37{ }^{\circ} \mathrm{C}$ com $5 \% \mathrm{CO}_{2}$ (modelo 3110, Forma Scientific, USA). Posteriormente, procedeu a expansão celular para frascos de cultivo de 25 , 75 e $150 \mathrm{~cm}^{2}$ (TPP, Suiça), assim como diminuição gradativa de SFB até $15 \%$ no meio RPMI.

\section{Produção de AcM IgG em meio sintético Hybridoma-SFM}

Os hibridomas cultivados em meio RPMI com 15 $\%$ de SFB $\left(37^{\circ} \mathrm{C}, 5 \%\right.$ de $\left.\mathrm{CO}_{2}\right)$ foram adaptados em meio Hybridoma-SFM (serum free médium H-SFM, Gibco Co., USA), adicionando gradualmente 25, 50 e $75 \%$ de H-SFM suplementado com $2 \mathrm{mM}$ de glutamina, $100 \mathrm{U} / \mathrm{mL}$ de penicilina e $100 \mu \mathrm{g} / \mathrm{mL}$ de estreptomicina (Gibco Co., USA) (HEUSSNER et al., 2007; KAWAMURA, informação pessoal, Kagawa University). 
A produção de AcM foi realizada em cultivo estático por aproximadamente 15 dias sem reposição de meio, até morte celular. O sobrenadante de cultivo contendo os AcM IgG antiAF foi centrifugado (2400x g, $10 \mathrm{~min}, 4{ }^{\circ} \mathrm{C}$; centrifuge $5804 \mathrm{R}$, Eppendorf, 3805 03551, Alemanha) para remover material celular. $\mathrm{O}$ volume total do sobrenadante foi avaliado quanto à concentração proteica a 280 nm (espectrofotômetro UV-VIS Cintra 20, GMB, Brasil); e atividade antiAFB .

\section{Determinação de proteína (IgG)}

A concentração proteica ( $\mathrm{IgG}$ ) foi determinada a $280 \mathrm{~nm}$, adotando coeficiente de absorção $\left(\mathrm{E}_{280}\right)$ de 1,35 para IgG (HARLOW; LANE, 1988a).

\section{Determinação de presença antiAF por i-ELISA}

IgG antiAF produzido nos sobrenadantes de meio sintético RPMI e H-SFM foi determinado por i-ELISA (Ensaio imunoenzimático indireto), sendo o protocolo similar ao descrito por Kawamura et al. (1988). As microplacas foram sensibilizadas com $100 \mu \mathrm{L}$ de $\mathrm{AFB}_{1}$-BSA $(2,5 \mu \mathrm{g} / \mathrm{mL}$, tampão Carbonato-Bicarbonato 0,1M pH 9,6) (Sigma Chemical Co., USA) e incubadas a $4{ }^{\circ} \mathrm{C}$ por $18 \mathrm{~h}$. Após 3 lavagens com PBST (PBS + 0,05 \% Tween 20), as placas foram bloqueadas com $200 \mu \mathrm{L}$ solução de ovalbumina 0,1 \% em PBS (Sigma Chemical Co., USA) e incubadas por $1 \mathrm{~h}$ a $37^{\circ} \mathrm{C}$. Após 3 lavagens com PBST, adicionou-se $100 \mu \mathrm{L}$ de sobrenadante do cultivo ou sobrenadante dialisado e incubadas a 25 ${ }^{\circ} \mathrm{C}$ por $1 \mathrm{~h}$. Após 4 lavagens com PBST, adicionouse $100 \mu \mathrm{L}$ de conjugado anti-IgG de camundongo marcado com horseradish peroxidase (Sigma Chemical Co., USA) diluído a 1:103 em PBST e incubadas a $25^{\circ} \mathrm{C}$ por $1 \mathrm{~h}$. Após 5 lavagens com PBST, adicionou-se $100 \mu \mathrm{L}$ da solução de substrato cromógeno TMB (3,3',5,5'-tetramethyl-benzidina) (Sigma Chemical Co., USA) por $30 \mathrm{~min}$ a $25^{\circ} \mathrm{C}$ e, a reação enzimática interrompida com $50 \mu \mathrm{L}$ de $\mathrm{H}_{2} \mathrm{SO}_{4} 1 \mathrm{M}$ e absorvância lida a $450 \mathrm{~nm}$ (leitora de ELISA, Bio-Tek Instruments ELX800, USA).
Purificação parcial de anticorpo monoclonal $\operatorname{Ig} G$ $\operatorname{antiAFB}_{1}$

Precipitação com (NH4) ${ }_{2} \mathrm{SO}_{4}$

O sobrenadante de cultivo com Ac antiAF foi adicionado de $\left(\mathrm{NH}_{4}\right)_{2} \mathrm{SO}_{4}$ (Sigma-Aldrich, USA e Synth, Brasil) sob agitação lenta até concentração final de 40,50 ou 60 \% de saturação para precipitação e purificação parcial de $\mathrm{IgG}$. O precipitado proteico obtido foi mantido a $4{ }^{\circ} \mathrm{C}$ por $16 \mathrm{~h}$ sob agitação, centrifugado (8000x g, $30 \mathrm{~min}, 4{ }^{\circ} \mathrm{C}$ ), transferido para tubo limpo e mantido a $-85^{\circ} \mathrm{C}$ (Kawamura, informação pessoal, Kagawa University).

\section{Diálise de proteína}

Para uso, o concentrado proteico precipitado com $\left(\mathrm{NH}_{4}\right)_{2} \mathrm{SO}_{4}$ foi descongelado e dissolvido em menor quantidade possível de PBS. A diálise (cut-off de 12000-16000 MM, tamanho $25 \mathrm{~mm} \mathrm{x}$ $16 \mathrm{~mm}$, Sigma Chemical Co., USA) foi realizada empregando-se PBS (4 x 1 L) a $4{ }^{\circ} \mathrm{C}$ por $16 \mathrm{~h}$. A solução de AcM parcialmente purificada foi dialisada em água ultrapura (4 x 1 L) para remoção de $\left(\mathrm{NH}_{4}\right)_{2} \mathrm{SO}_{4}$. A concentração proteica (IgG) foi determinada no sobrenadante pós-precipitação com $\left(\mathrm{NH}_{4}\right)_{2} \mathrm{SO}_{4}$ e pós-diálise e presença do AcM analisado por i-ELISA.

\section{Eletroforese em SDS-PAGE}

Para avaliar a pureza e quantidade de AcM produzido por hibridoma AF2 no meio RPMI e H-SFM foi realizada eletroforese em gel de poliacrilamida (SDS-PAGE), descrita por Laemmli (1970). O AcM (1 mg/mL) foi diluído em tampão de amostra 3 vezes concentrado e, alíquota de $3,75 \mu \mathrm{L}$, correspondente a 2,5 $\mu \mathrm{g}$ de proteína, foi aplicada no gel paralelamente com $5 \mu \mathrm{L}$ do padrão de marcador molecular (BenchMark ${ }^{\mathrm{TM}}$ Protein Ladder, Invitrogen, Carlsbad, USA). O gel de concentração (stacking) foi de $5 \%$ de acrilamida, enquanto que de corrida (running) foi $10 \%$. Após corrida por $1 \mathrm{~h}$ sob 
20 mA, o gel foi corado com solução de Coomassie blue (Coomassie Brilliant Blue R, Sigma, USA) e descorado com ácido acético:metanol:água (1:4:5), para a visualização e distinção de bandas proteicas.

\section{ic-ELISA}

A capacidade da ligação de $\mathrm{AcM}$ antiAFB (produzido em $100 \% \mathrm{H}-\mathrm{SFM} 1^{\mathrm{a}}$ precipitação, 50 e $75 \%$ H-SFM) ao antígeno específico $\left(\mathrm{AFB}_{1}\right)$ foi analisada por ELISA competitivo indireto (KAWAMURA et al., 1988, adaptado). As microplacas foram sensibilizadas, bloqueadas e lavadas conforme descrito para i-ELISA. Após a etapa de bloqueio e lavagem, adicionou-se $50 \mu \mathrm{L}$ de $\mathrm{AFB}_{1}$ padrão nas concentrações de 0 a $200 \mathrm{ng} /$ $\mathrm{mL}$ (Sigma Chemical Co., USA) seguida $50 \mu \mathrm{L}$ de AcM antiAFB $(1,14 \mu \mathrm{g} / \mathrm{mL}$ do Ac produzindo em $100 \% \mathrm{H}-\mathrm{SFM} 1^{\text {a }}$ precipitação; $1,66 \mu \mathrm{g} / \mathrm{mL}$ do Ac produzindo em $50 \% \mathrm{H}-\mathrm{SFM} ; 2,85 \mu \mathrm{g} / \mathrm{mL}$ do Ac produzindo em $50 \% \mathrm{H}$-SFM diluídos em PBST), e agitou-se levemente a placa Após incubação a 25 ${ }^{\circ} \mathrm{C}$ por $1 \mathrm{~h}$, as placas foram submetidas a 5 lavagens com PBST. As etapas posteriores foram executadas conforme anteriormente descrito para i-ELISA.

\section{Resultados e Discussão}

A viabilidade celular pós-descongelamento rápido de hibridoma $\mathrm{AF} 2$ (mantida a $-185^{\circ} \mathrm{C}$ desde $06 / 04 / 2004$ ) foi de $4,27 \%$. Os fatores prejudiciais relevantes à viabilidade celular consistem da exaustão de nutrientes, acúmulo de compostos indesejáveis provenientes do metabolismo, restrição de oxigênio e $\mathrm{CO}_{2}$ devido ao longo período congelado (LEGAZPI et al., 2005). Soma-se ainda, o uso de dimetilsulfóxido (DMSO) (Synth, Brasil) como agente crioprotetor, capaz de injuriar células devido à interação com membrana celular. A toxicidade de DMSO aumenta em temperatura alta, portanto recomenda-se adicionar DMSO em soro (1:9) mantido a $4{ }^{\circ} \mathrm{C}$ e imediatamente iniciar o processo de congelamento (WEWETZER; DILMAGHANI,
2001). Recomenda-se o congelamento lento de criotubos em recipiente específico para congelamento (Bio Freezing Vessel, Bicell, Nihon Freezer Co., Japão) mantendo em ultra-freezer $-85^{\circ} \mathrm{C}$ por um dia, antes de armazenar a $-185{ }^{\circ} \mathrm{C}$. Todavia, o descongelamento em banho a $37^{\circ} \mathrm{C}$ e centrifugação devem ser rápidos, devido à toxicidade de DMSO. Embora os resultados apresentassem baixo valor de viabilidade pós-criopreservação, a contagem de 4,2 x $10^{5}$ células viáveis/mL permitiu prosseguir para a etapa de expansão celular.

O desenvolvimento de meio de cultivo ideal visando obtenção de produto celular específico tem sido processo empírico em contínuo avanço (CHU; UENO, 1977; GROOPMAN et al., 1984; KAWAMURA et al., 1988.; CANDLISH; SMITH; STIMSON, 1989; HOLTZAPPLE et al.,1996; KONDO et al., 2000; HEILMANN et al., 2007; HEUSSNER et al., 2007). A exemplo, o cultivo do hibridoma AF2 em RPMI iniciou-se tamponando o meio com bicarbonato de sódio; a adição de HEPES garantiu maior tempo de estabilidade do meio por manter $\mathrm{pH}$ fisiológico, mesmo sob mudança na concentração de $\mathrm{CO}_{2}$ devido a respiração celular (BAICU; TAYLOR, 2002).

No nosso ensaio introduziu-se $40 \mu \mathrm{g} / \mathrm{mL}$ de gentamicina no meio RPMI, para inibir a contaminação bacteriana durante o cultivo. Este antibiótico apresenta vida-média de 15 dias no meio de cultura a $37{ }^{\circ} \mathrm{C}$, sendo que o uso recomendando de até $50 \mu \mathrm{g} / \mathrm{mL}$ de gentamicina tem favorecido a expansão celular (HARLOW; LANE, 1988b).

Salienta-se a importância da suplementação de meio RPMI com soro bovino fetal (SFB) na recuperação e expansão do hibridoma, por conferir fatores hormonais de estimulação e proteínas para transporte de hormônios, minerais, lipídios e outros fatores naturais essenciais na multiplicação celular (AYBAY; IMIR, 2000; LEGAZPI et al., 2005; EVEN; SANDUSKY; BARNARD, 2006). A L-glutamina destaca-se como substrato fundamental no cultivo de hibridoma, constituindo-se em fonte 
primária de nitrogênio (LEGAZPI et al., 2005; OKESON; RILEY, 2001). A exaustão de glutamina no meio de cultura pode cessar a multiplicação de hibridoma (OZTURK; PALSSON, 1991).

Paralelamente, o desenvolvimento de meio H-SFM visou eliminar problemas inerentes ao uso de SFB, i.e. diminuir o custo do reagente e perigo de contaminação perante determinados patógenos microbianos como príon, vírus e micoplasma (LEGAZPI et al., 2005; EVEN; SANDUSKY; BARNARD, 2006). Em adição a benefícios técnicos e de segurança, a sua composição de caráter definida permite controle no desenvolvimento de cultivo celular, principalmente perante facilidade na purificação de AcM (LEGAZPI et al., 2005; EVEN; SANDUSKY; BARNARD, 2006).

Assim, o crescimento inicial de hibridoma em $100 \%$ de meio RPMI foi adaptado através de adição gradual de meio H-SFM suplementado com L-glutamina, penicilina e estreptomicina na sequência de 25, 50, 75 e $100 \%$. Para confirmar a capacidade produtora de IgG antiAFB ${ }_{1}$ em hibridoma recuperado, assim como a produtividade de AcM em $100 \%$ de meio RPMI antes de prosseguir adaptação e, melhoramento do cultivo adicionando H-SFM, procedeu-se i-ELISA.

Adicionando $40 \%$ de $\left(\mathrm{NH}_{4}\right)_{2} \mathrm{SO}_{4}$ emsobrenadantes de cultivo do hibridoma AF2 em $100 \%$ de RPMI, assim como adicionado de 25, 50 e $75 \%$ de H-SFM, obteve precipitação satisfatória. Entretanto, a mesma saturação de $\left(\mathrm{NH}_{4}\right)_{2} \mathrm{SO}_{4}$ não permitiu precipitação adequada de sobrenadante em cultivo com $100 \%$ de H-SFM (precipitado delgado e frágil sem aderência ao tubo). Aumentando a saturação de $\left(\mathrm{NH}_{4}\right)_{2} \mathrm{SO}_{4}$ para $50 \%$ ocorreu formação de precipitado consistente, onde se concentrou maior atividade antiAFB, embora o sobrenandante ainda mantivesse turvo ( $1^{\mathrm{a}}$ precipitação). Assim, neste sobrenadante turvo adicionou-se $\left(\mathrm{NH}_{4}\right)_{2} \mathrm{SO}_{4}$ até $60 \%$ de saturação, obtendo-se precipitação parcial ( $2^{\mathrm{a}}$ precipitação). Segundo Harlow e Lane (1988c), a maioria de outros componentes séricos não precipitam na faixa de 40 a $50 \%$ de saturação, tornando inexpressiva a distinção destas concentrações. Miyamoto, Hamada e Kawamura (2008) testando precipitação de AcM antiAFG produzido no meio H-SFM com 40, 50 e $60 \%$ de $\left(\mathrm{NH}_{4}\right)_{2} \mathrm{SO}_{4}$, obteve melhor resultado com $60 \%$ de saturação. Outrossim, os nossos resultados apontaram melhor rendimento empregando $50 \%$ de saturação.

Os precipitados foram estocados a $-85^{\circ} \mathrm{C}$, sendo descongelados a $4{ }^{\circ} \mathrm{C}$ somente no momento de diálise para evitar a desnaturação proteica, devendose evitar congelamento pós-diálise, já que ocorre perda drástica de atividade.

A Tabela 2 analisa o teor proteico estimado a 280 nm, obtido no decorrer das etapas de pós-cultivo, pós-precipitação com $\left(\mathrm{NH}_{4}\right)_{2} \mathrm{SO}_{4}$ e pós-diálise. O hibridoma AF2 produziu em média, 2,94 mg/ $\mathrm{mL}$ de proteína. Maior teor estimado de proteínas $(9,88 \mathrm{mg} / \mathrm{mL}$ em $100 \%$ RPMI e $10,88 \mathrm{mg} / \mathrm{mL}$ em $25 \% \mathrm{H}-\mathrm{SFM}$ ) ocorreu em cultivo contendo maior proporção de RPMI, indicando interferência de SFB na leitura a $280 \mathrm{~nm}$. Em contraste, cultivos em meio contendo maior proporção de H-SFM apresentou menor teor proteico $(2,29$ e $1,80 \mathrm{mg} / \mathrm{mL}$ em 100 $\%$ H-SFM. $1^{\mathrm{a}}$ e $2^{\mathrm{a}}$ precipitação, respectivamente), mas pode-se inferir que este corresponda ao valor equivalente mais próximo à concentração real de anticorpo produzido. Em suma, o processo de produção de AcM empregando hibridoma AF2 atingiu valor estimado de $385 \mathrm{mg}$ de proteína total, sendo que maior atividade antiAFB ${ }_{1}$ ocorreu no cultivo empregando maior proporção do meio H-SFM. Em todas as fases de cultivo apresentaram presença de $\mathrm{AcM}_{\text {antiAFB }}$ (Tabela 2 e Figura 1). 
Tabela 2. Produção estimada de proteína e atividade antiAFB para diferentes condições de saturação $\left(\mathrm{NH}_{4}\right)_{2} \mathrm{SO}_{4}$.

\begin{tabular}{|c|c|c|c|c|c|}
\hline \multirow{2}{*}{$\begin{array}{r}\text { Precipitação } \\
\text { Saturação } \\
\left(\mathrm{NH}_{4}\right)_{2} \mathrm{SO}_{4}\end{array}$} & \multirow[b]{2}{*}{ Meio de cultura (\%) } & \multicolumn{3}{|c|}{ Proteína Total Estimada a 280 nm (mg) } & \multirow{2}{*}{$\begin{array}{c}\text { i-ELISA } \\
\text { (Pós-diálise) }\end{array}$} \\
\hline & & Pós-cultivo & Pós-( $\left.\mathrm{NH}_{4}\right)_{2} \mathrm{SO}_{4}$ & Pós-diálise & \\
\hline \multirow{2}{*}{$40 \%$} & RPMI $(100)^{a}$ & 682,5 & 111,9 & 108,68 & + \\
\hline & H-SFM $(25)^{\mathrm{a}}$ & 734 & 108 & 97,92 & + \\
\hline \multirow[t]{2}{*}{$40 \%$} & H-SFM $(50)^{\mathrm{a}}$ & 426,67 & 37,95 & 34,2 & + \\
\hline & H-SFM $(75)^{\mathrm{a}}$ & 320 & 23,19 & 19,92 & + \\
\hline $50 \%$ & H-SFM $(100)^{b}$ & 266,6 & 17,1 & 13,74 & + \\
\hline $60 \%$ & H-SFM $(100)^{c}$ & & 16,02 & 12,6 & + \\
\hline
\end{tabular}

Estimação em 1 tubo; o restante $\mathrm{AcM}$ precipitado em $\left(\mathrm{NH}_{4}\right)_{2} \mathrm{SO}_{4}$ foi mantido congelado até o momento de uso.

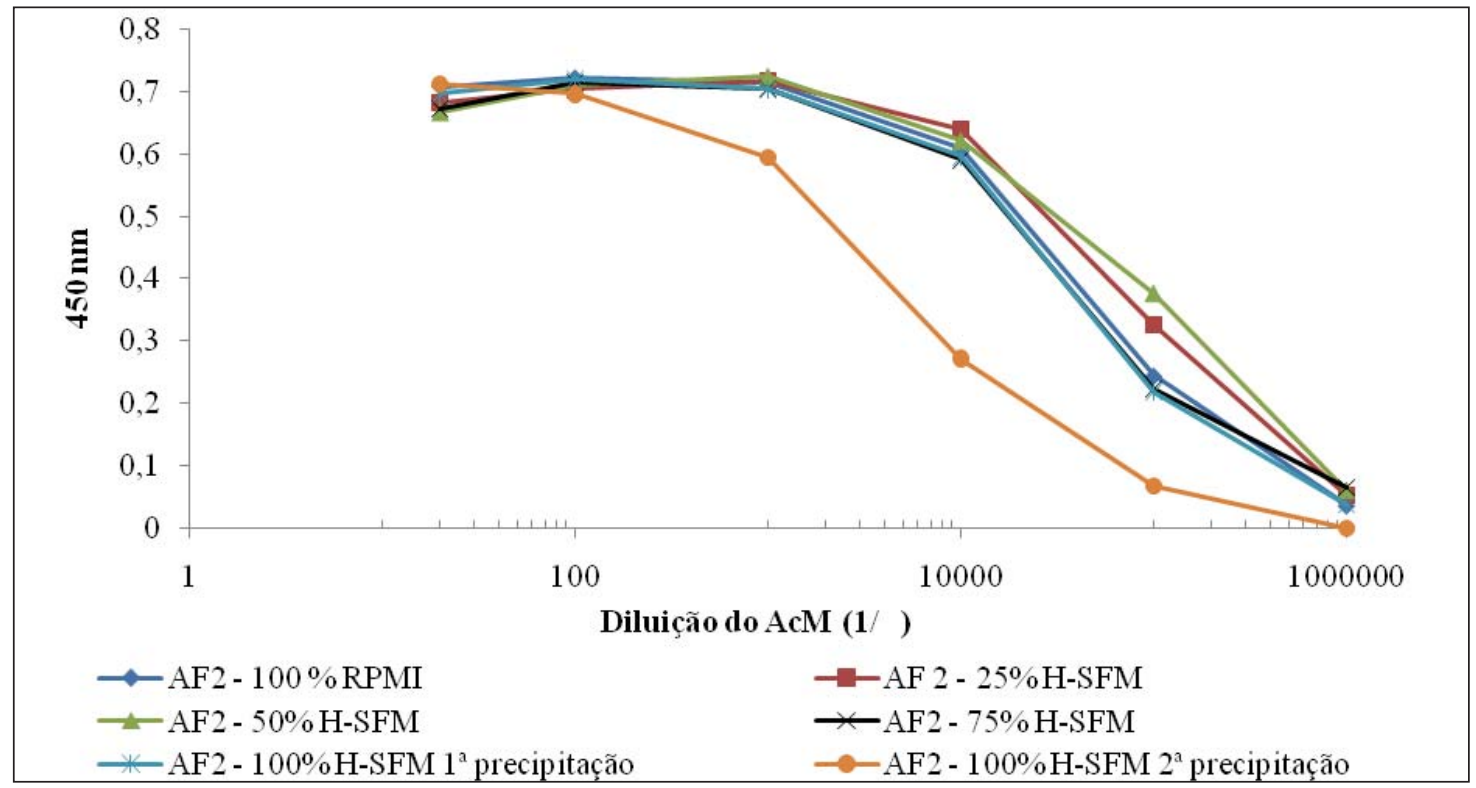

Figura 1. AcM antiAFB em diferentes fases de cultivo. Nível de antiAFB ${ }_{1}$ em D.O a $450 \mathrm{~nm}$ foi avaliado por i-ELISA em cultivo de hibridoma AF2 em meio $100 \%$ RPMI, $25 \%, 50 \%, 75 \%, 100 \%$ H-SFM (etapa pós-diálise do precipitado com $\left(\mathrm{NH}_{4}\right)_{2} \mathrm{SO}_{4}$.

Eletroforese em SDS-PAGE foi realizada para analisar a pureza de AcM produzido em cada etapa do cultivo utilizando meio RPMI e H-SFM (Figura 2). O uso de mercaptoetanol (agente redutor) no preparo das amostras (IgG) rompe as pontes dissulfeto, separando em cadeias pesadas $(50 \mathrm{kDa})$ e cadeias leves (25 kDa) (BOENISCH, 2001). O resultado confirma presença das bandas de $\pm 55 \mathrm{kDa}$ e $\pm 25 \mathrm{kDa}$, principalmente em $100 \%$ de H-SFM na $1^{\mathrm{a}}$ precipitação, $75 \%$ e $50 \%$ de H-SFM. 


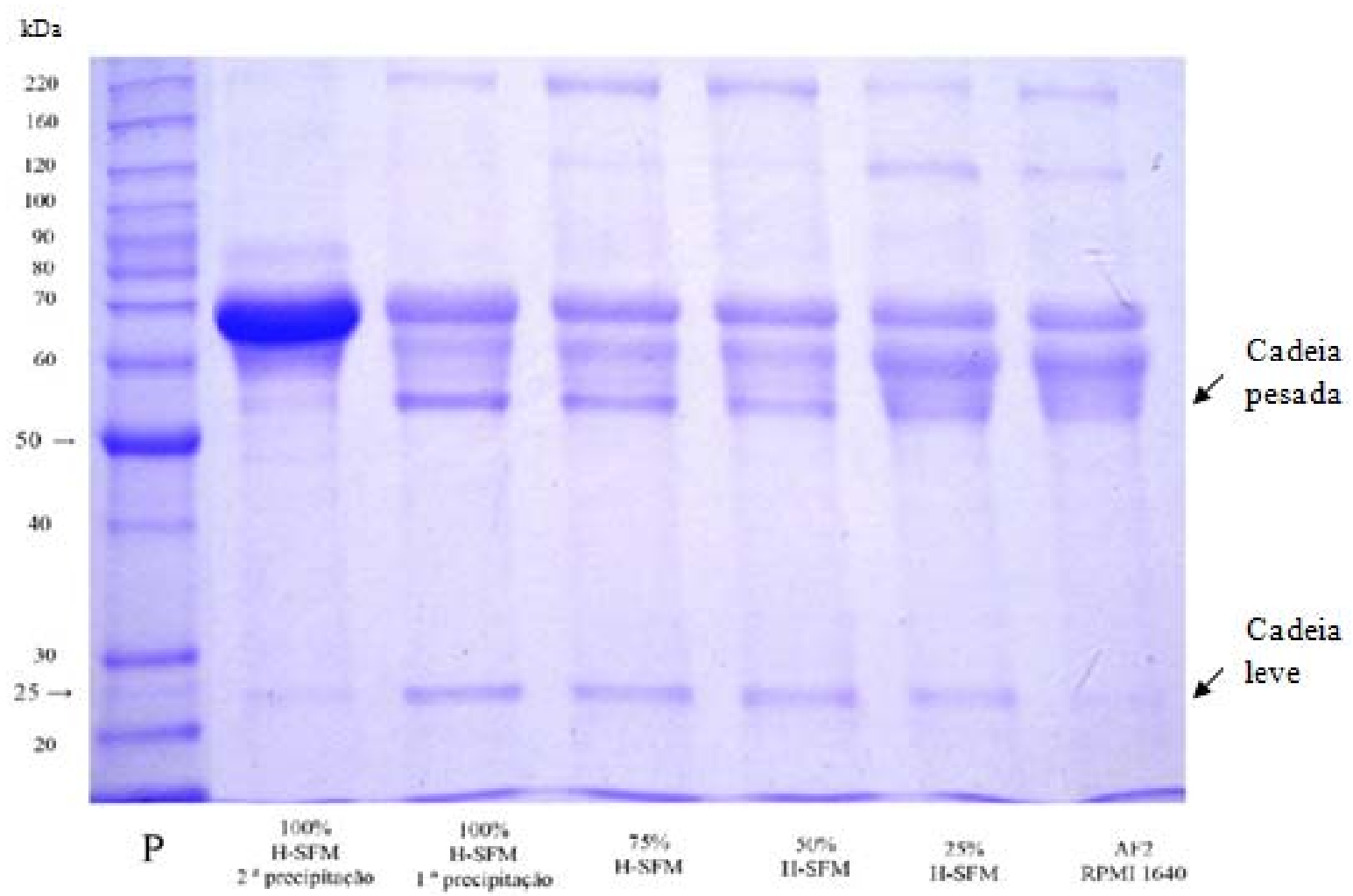

Figura 2. Análise de $A c M$ antiAFB . Grau da pureza de $A c M$ antiAFB ${ }_{1}$ produzido por hibridoma AF2: análise por SDS-PAGE de cultivo em meio $100 \%$ RPMI e RPMI adicionado de 25, 50, 75 e $100 \%$ H-SFM (etapa pós-diálise do precipitado com $\left.\left(\mathrm{NH}_{4}\right)_{2} \mathrm{SO}_{4}\right)$.

P: marcador de proteína (BenchMarkTM Protein Ladder, Invitrogen, USA). As setas apontam as cadeias pesadas ( \pm $55 \mathrm{kDa})$ e cadeias leves $( \pm 25 \mathrm{kDa})$ do anticorpo, originadas pela quebra das pontes de dissulfeto.

O perfil eletroforético mostrou várias bandas inespecíficas precipitadas pelo $\left(\mathrm{NH}_{4}\right)_{2} \mathrm{SO}_{4}$, mas não correspondente ao anticorpo. Segundo Harlow e Lane (1988c), este sal também precipita outras proteínas de alta massa molecular, bem como proteínas podem aderir ao precipitado floculante, aumentando impurezas adicionais. Além disso, essas bandas inespecíficas podem ser originarias de resto celulares, devido ao cultivo do hibridoma até morte celular, visando obter maior quantidade de anticorpo.

Após a realização de eletroforese em SDS-PAGE foram escolhidos AcM produzidos em meio 100 $\%$ H-SFM ( $1^{\text {a }}$ precipitação), $75 \%$ e $50 \%$ H-SFM para proceder ic-ELISA e confirmar capacidade de ligação os $\mathrm{AcM}$ antiAFB ${ }_{1}$ ao antígeno específico $\left(\mathrm{AFB}_{1}\right)$.
Antes de ic-ELISA, procedeu-se i-ELISA com as soluções dialisadas (diluição de 1:20 a 1:10 de Ac) (Figura 1). Assim, pôde estimar $50 \%$ da máxima ligação dos anticorpos produzidos e ser o título empregado no ic-ELISA (em torno de 1:2000, correspondendo a 1,14; 1,66 e $2,85 \mu \mathrm{g} / \mathrm{mL}$ de AcM produzindo em $100 \% \mathrm{H}-\mathrm{SFM} 1^{\mathrm{a}}$ precipitação; $75 \mathrm{e}$ $50 \% \mathrm{H}-\mathrm{SFM}$, respectivamente).

O ic-ELISA mostrou que $100 \% 1^{\text {a }}$ precipitação, 50 e $75 \%$ H-SFM apresentam um adequado

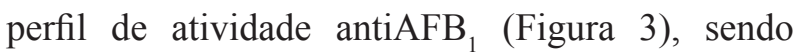
apropriados para aplicá-los como bioferramentas para desenvolvimento de métodos para detecção de AF empregando anticorpo. 


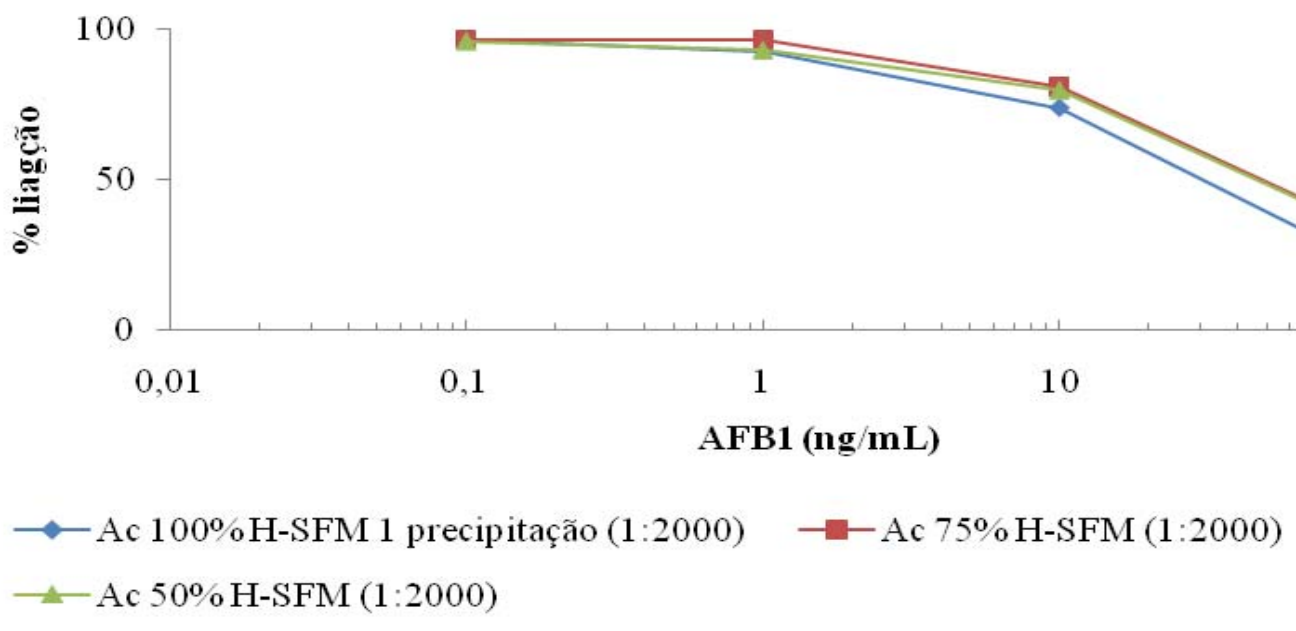

Figura 3. Atividade de $A c M$ antiAFB ${ }_{1}$ no cultivo de hibridoma AF2 em meio RPMI adicionado de 50, 75 e $100 \%$ H-SFM por ic-ELISA, utilizando $\mathrm{AFB}_{1}$ na concentração de 0,$1 ; 1 ; 10 ; 100$ e $200 \mathrm{ng} / \mathrm{mL}$ para competição.

\section{Conclusão}

O domínio de princípios biológicos básicos é fundamental para a inovação tecnológica envolvendo bioferramentas. O sucesso depende de cuidados e detalhes críticos, que viabilizam o cultivo de hibridoma produtor de AcM tendo como meta a produção ilimitada de Ac destinado à primeira etapa do desenvolvimento de técnicas imunoquímicas. A introdução de meio sintético como H-SFM isento de SFB permite obtenção de reagente com maior pureza, baixo custo e menor perigo; a produção em condição nacional possibilitaria autossuficiência perante reagentes essenciais no diagnóstico rápido atualmente dependente de kits importados.

\section{Agradecimentos}

Os autores agradecem a CAPES/MEC (Coordenadoria de Aperfeiçoamento de Pessoa de Nível Superior) pela bolsa de Mestrado às duas primeiras autoras. Ao CNPq (Conselho Nacional de Pesquisa e Desenvolvimento Científico e Tecnológico), UGF - Fundo Paraná /SETI e
Fundação /Araucária pelo apoio financeiro; ao CNPq, pelas modalidades de bolsa desde Produtividade em Pesquisa, Doutorado e Apoio Técnico. Às doutorandas Joice Sifuentes dos Santos e Dani Luce Doro da Silva pela colaboração nas técnicas laboratoriais.

\section{Referências}

ANKLAM, E.; STROKA, J.; BOENKE, A. Acceptance of analytical methods for implementation of EU legislation with a focus on mycotoxins. Food Control, Oxford, v. 13, n. 3, p. 173-183, abr. 2002.

ARDIC, M.; KARAKAYA, Y; ATASEVER, M.; DURMAZ, H. Determination of aflatoxin $\mathrm{B}_{1}$ levels in deep-red ground pepper (isot) using immunoaffinity column combined with ELISA. Food and Chemical Toxicology, Oxford, v. 46, n. 5, p. 1596-1599, maio 2008.

AYBAY, C.; IMIR, T. Development of a rapid, singlestep procedure using protein $\mathrm{G}$ affinity chromatography to deplete fetal calf serum of its IgG andto isolate murine IgG1 monoclonal antibodies from supernatants of hybridoma cells. Journal of Immunological Methods, Amsterdam, v. 233, n. 1/2, p.77-81, jan. 2000. 
BAICU, S. C.; TAYLOR, M. J. Acid-base buffering in organ preservation solutions as a function of temperature: new parameters for comparing buffer capacity and efficiency. Cryobiology, San Diego, v. 45, n. 1, p. 33-48, ago. 2002.

BOENISCH, T. Handbook immunochemical staining methods. 3 rd edition. California, USA: DAKO Corporation, 2001. $68 \mathrm{p}$.

BRADBURN, N.; COKER, R. D.; BLUNDEN, G. A comparative study of solvent extraction efficiency and the performance of immunoaffinity and solid phase columns on the determination of aflatoxin $\mathrm{B}_{1}$. Food Chemistry, London, v. 52, n. 2, p. 179-185, 1995.

BRASIL. Agência Nacional de Vigilância Sanitária ANVISA. 2002. Resolução RDC $n^{\circ} 274$. Regulamento técnico sobre limites máximos de aflatoxinas admissíveis no leite, no amendoim, no milho, constante do anexo desta Resolução. Disponível em: <http://e-legis.anvisa. gov.br/leisref/public/ showAct.php?id=1653>. Acesso em: 18 ago. 2007.

CALLERI， E.; MARRUBINI，G.; BRUSOTTI，G.; MASSOLINI, G.; CACCIALANZA G. Development and integration of an immunoaffinity monolithic disk for the on-line solid-phase extraction and HPLC determination with fluorescence detection of aflatoxin $\mathrm{B}_{1}$ in aqueous solutions. Journal of Pharmaceutical and Biomedical Analysis, Amsterdam, v. 44, n. 2, p. 396-403, jun. 2007.

CANDLISH, A. A. G.; SMITH, J. E.; STIMSON, W. H. Monoclonal antibody for micotoxins. Biotechnology Advances, New York, v. 7, n. 3, p. 401-418, 1989.

CHIAVARO, E.; DALL'ASTA, C.; GALAVERNA, G.; BIANCARDI, A.; GAMBARELLI, E.; DOSSENA, A.; MARCHELLI, R. New reversed-phase liquid chromatography method to detect aflatoxins in food and feed with cyclodextrins as fluorescence enhancers added to the eluent. Journal of Chromatography A, Amsterdam, v. 937, n. 1/2, p. 31-40, dez. 2001.

CHO, S. H.; LEE, C. H.; JANG, M. R.; SON, Y. W.; LEE, S. M.; CHOI, I. S; KIM, S. H.; KIM, D. B. Aflatoxins contamination in spices and processed spice products commercialized in Korea. Food Chemistry, London, v. 107, n. 3, p. 1283-1288, abr. 2008.

CHU, F. S.; UENO, I. Production of antibody against aflatoxin $\mathrm{B}_{1}$. Applied and Environmental Microbiology, Washington, v. 33, n. 5, p. 1125-1128, maio 1977.

EDINBORO, L. E.; KARNES, H. T. Determination of aflatoxins $B_{1}$ in sidestream cigarette smoke by immunoaffinity column extration coupled with liquid chromatography/mass spectrometry. Journal of
Chromatography A, Amsterdam, v. 1083, n. 1/2, p. 127 132, ago. 2005.

EVEN, M. S.; SANDUSKY, C. B.; BARNARD, N. D. Serum-free hybridoma culture: ethical, scientific and safety considerations. Trends in Biotechnology, Amsterdam, v. 24, n. 3, p. 105-108, mar. 2006.

GROOPMAN, J. D.; TRUDEL, L. J.; DONAHUE, P. R.; MARSHAK-ROTHSTEIN, A.; WOGAN, G. N. Highaffinity monoclonal antibodies for aflatoxin and their application to solid-phase immunoassays. Biochemistry, New York, v.81, n. 24, p. 7728-7731, dez. 1984.

HARLOW, E.; LANE, D. Growing hybridomas. In: (Ed.). Antibodies: a laboratory manual. New York: Cold Spring Harbor Laboratory, 1988b. p. 245281.

. Protein tchniques. In: (Ed.). Antibodies: a laboratory manual. New York: Cold Spring Harbor Laboratory, 1988a. p. 673.

Storing and prifying antibodies. In:

(Ed.). Antibodies: a laboratory manual. New York: Cold Spring Harbor Laboratory, 1988c. p. 245-281.

HEILMANN, K.; GROTH, T. H.; SCHOSSIG, M.; LENDLEIN, A.; MICHEEL, B. Modulation of hybridoma cell growth and antibody production by coating cell culture material with extracellular matrix proteins. Biochemical Engineering Journal, Amsterdam, v. 35, n. 3, p. 301-308, ago. 2007.

HEUSSNER, A. H.; MOELLER, I.; DAY, B. W.; DIETRICH, D. R.; O'BRIEN, E. Production and characterization of monoclonal antibodies against ochratoxin B. Food and Chemical Toxicology, Oxford, v. 45, n. 5, p. 827-833, maio 2007.

HOLTZAPPLE, C. K.; CARLIN,R. T. I.; ROSE, B. G.; KUBENA, L. F.; STANKER, L. H. Characterization of monoclonal antibodies to aflatoxin M1 and molecular modeling studies of related aflatoxins. Molecular Immunology, Oxford, v. 33. n. 11/12, p. 939-946, ago. 1996.

INTERNATIONAL AGENCY FOR RESEARCH ON CANCER. Aflatoxins. In: IARC. Monographs on the evaluation of carcinogenic risk to humans: some traditional herbal medicines, some mycotoxins, naphthalene and sryrene. Lyon, France: IARC, 2002. v. 82, p. 171-300.

IP, S. P.; CHE, C. T. Determination of aflatoxins in Chinese medicinal herbs by high-performance liquid chromatography using immunoaffinity column cleanup Improvement of recovery. Journal of Chromatography A, Amsterdam, v. 1135, n. 2, p. 241-244, dez. 2006. 
JAIMEZ, J.; FENTE, C. A.; VAZQUEZ, B. I.; FRANCO, C. M.; CEPEDA, A.; MAHUZIER, G.; PROGNON, P. Review. Application of the assay of aflatoxins by liquid chromatography with fluorescence detection in food analysis. Journal of Chromatography A, Amsterdam, v. 882, n. 1/2, p. 1-10, jun. 2000.

KAWAMURA, O.; NAGAYAMA, S.; SATO, S.; OHTANI, K.; UENO, I.; UENO, Y. A monoclonal antibody-based enzyme-linked immunosorbent assay of aflatoxin $\mathrm{B}_{1}$ in peanut products. Mycotoxin Research, Mainz, v. 4, p. 75-87, 1988.

KONDO, F.; MATSUMOTO, H.; YAMADA, S.; TSUJI, K.; UENO, Y.; HARADA, K. I. Immunoaffinity purification method for detection and quantification of microcystins in lake water. Toxicon, Oxford, v. 38, n. 6, p. 813-823, jun. 2000.

KRSKA, R.; SCHUBERT-ULLRICH, P.; MOLINELLI, A.; SULYOK, M.; MACDONALD, S.; CREWS, C. Mycotoxin analysis: An update. Food Additives and Contaminants, London, v. 25, n. 2, p. 152-163, fev. 2008.

LAEMMLI, U. K. Cleavage of structural proteins during the assembly of the head of bacteriophage T4. Nature, London, v. 227, p. 680-685, ago. 1970.

LEGAZPI, L.; DÍAZ, J.; LACA, A.; DÍAZ, M. Kinetic analysis of hybridoma cell culture in a protein-free medium: substrate and agitation effects. Biochemical Engineering Journal, Amsterdam, v. 26, n. 2/3, p. 122130, nov. 2005.

LUPPA, P. B.; SOKOLL, L. J.; CHAN, D. W. Review. Immunosensores - principles and application to clinical chemistry. Clinica Chimica Acta, Amsterdam, v. 314, n. 1/2, p. 1-26, dez. 2001.

MIYAMOTO, K.; HAMADA, A.; KAWAMURA, O. Determination of aflatoxins in corn and peanut by an immunoaffinity column bound AF.2 monoclonal
antibody-HPLC method. Kagawa Daigaku Nogakubu Gakujutsu Hokoku, Kagawa, n. 113, p. 75-81, 2008.

OKESON, C. D.; RILEY, M. R. Glutamine replenishment and ammonia removal in hybridoma cell cultures via immobilized glutamine synthetase. Biochemical Engineering Journal, Amsterdam, v. 9, n. 2, p. 125-133, dez. 2001.

OZTURK, S. S.; PALSSON, B. O. Growth, metabolic, and antibody production kinetics of hybridoma cell culture. 1. Analysis of data from controlled batch reactors. Biotechnology Progress, New York, v. 7, n. 6, p. 471480, nov./dez. 1991.

PRIETO-SIMÓN, B.; NOGUER, T.; CAMPÀS, M. Emerging biotools for assessment of mycotoxins in the past decade. Trends in Analytical Chemistry, Amsterdam, v. 26, n. 7, p. 689-702, jul./ago. 2007.

SANCHEZ, F. G.; DIAZ, A. N.; HERRERA, R. G.; SAN JOSE, L. P. Development and characterisation of an immunoaffinity chromatographic column for the on-line determination of the pesticide triclopyr. Talanta, Oxford, v. 71, n. 3, p. 1411-1416, fev. 2007.

VAN EGMOND, H. P.; SCHOTHORST, R. C.; JONKER, M. A. Review Regulations relating to mycotoxins in food Perspectives in a global and European context. Analytical and Bioanalytical Chemistry, Heidelberg, v. 389, n. 1, p. 147-157, set. 2007.

WEWETZER, K.; DILMAGHANI, K. Exposure to dimethyl sulfoxide at $37^{\circ} \mathrm{C}$ prior to freezing significantly improves the recovery of criopreserved hybridoma cells. Cryobiology, San Diego, v. 43, n. 3, p. 288-292, nov. 2001.

XIULAN, S.; XIAOLIAN, Z.; JIAN, T.; XIAOHONG, G.; JUN, Z.; CHU, F. S. Development of an immunochromatographic assay for detection of aflatoxin $\mathrm{B}_{1}$ in foods. Food Control, Guilford, v. 17, n. 4, p. 256262, abr. 2006. 
